\title{
Organic Molecules of Intrinsic Microporosity
}

\author{
Neil B. McKeown*a (iD) \\ a EaStCHEM School of Chemistry, University of Edinburgh, David Brewster Road, \\ Edinburgh EH9 3FJ, United Kingdom \\ neil.mckeown@ed.ac.uk
}

Received: 08.10.2019

Accepted after revision: 20.11.2019

DOI: 10.1055/s-0039-3402512; Art ID: om-19-0016-rev

License terms: CC $(1)$

(c) 2020. The Author(s). This is an open access article published by Thieme under the terms of the Creative Commons Attribution-NonDerivative-NonCommercial-License, permitting copying and reproduction so long as the original work is given appropriate credit. Contents may not be used for commercial purposes, or adapted, remixed, transformed or built upon. (https://creativecommons.org/licenses/by-nc-nd/4.0/).

Abstract Organic molecules of intrinsic microporosity (OMIMs) are rigid molecules with an awkward shape that are designed to pack space inefficiently in the solid state maximizing free volume and thereby generating apparent microporosity as determined by gas adsorption. In this perspective article, the origin of the OMIM concept is explained and the progress in its realization both by synthesis and packing simulation is reviewed.

Key words Intrinsic microporosity, organic molecules, gas adsorption, packing simulations

\section{Introduction}

Over the last two decades, there has been an intense global research effort to prepare porous crystalline materials from organic molecular components to meet the requirements for improved catalysis, adsorption, molecular storage, and separations. ${ }^{1}$ This research effort has led to the discovery of a variety of materials known by an ever-increasing number of acronyms including porous coordination polymers (PCPs), ${ }^{2}$ metal-organic frameworks (MOFs), ${ }^{3}$ covalent organic frameworks (COFs), ${ }^{4}$ and hydrogen-bonded organic frameworks. ${ }^{5}$ As their names imply, these materials involve the formation of coordination or covalent bonds between the molecular components to ensure spatial separation and, hence, the creation of an open-ordered framework. The bondforming reactions are reversible so that structural errors can be corrected, which is necessary to obtain crystallinity. However, such a coordination or covalent framework is not a prerequisite for stable porosity within crystalline materials as now demonstrated by many examples of

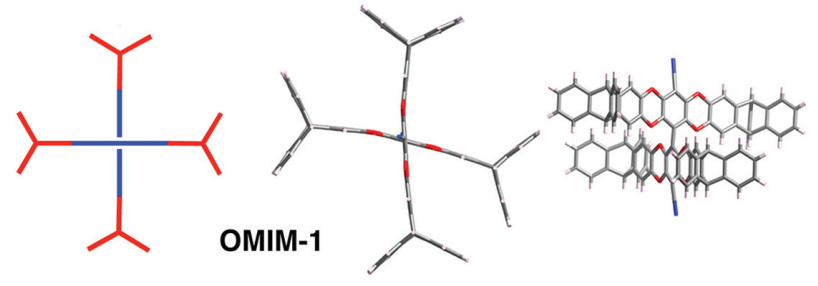

porous molecular crystals. ${ }^{6}$ A large proportion of molecular crystals are based on cages ${ }^{7}$ or macrocycles, both of which act as prefabricated pores, ${ }^{8}$ but others are simply organic molecules that pack inefficiently but with a crystalline order. $^{9}$ For all of these crystalline materials, the porosity is only revealed on the removal of the solvent of crystallization, a process often termed activation, which needs to occur without the structural collapse of the crystal. Despite the understandable fascination with well-ordered porous materials-many of which have aesthetically appealing crystal structures-wholly amorphous materials can also be highly porous as demonstrated by the commercially ubiquitous activated carbons. In parallel to the $\mathrm{PCP} / \mathrm{MOF} / \mathrm{COF}$ revolution, there has also been increasing interest in making amorphous porous organic polymers (POPs), usually via the irreversible formation of three or more bonds between molecular components to form a rigid network polymer. Some of these network POPs, such as hypercrosslinked polymers $(\mathrm{HCPs})^{10}$ and network polymers of intrinsic microporosity (PIMs), ${ }^{11}$ can be highly porous with HCPs prepared from the Yamamoto coupling reaction of tetrakis(4bromophenyl)methane, in particular, demonstrating porosity that rivals most MOFs and COFs. ${ }^{12}$ The porosity of most POPs is ensured by a three-dimensional (3D) network of covalent bonds so that they are stable but intractable solids and therefore share the difficulties of processing from solution with conventional porous materials. In contrast, PIMs generate porosity from the inefficient amorphous packing of their rigid and contorted macromolecular chains. ${ }^{13}$ Many PIMs do not have a 3D network structure and are therefore soluble in common organic solvents. PIMs are prepared via stepgrowth polymerizations based on the formation of ladder-like benzodioxin ${ }^{13 a}$ or Tröger's base linkages. ${ }^{14}$ It was noted that oligomeric by-products that were removed during the purification of PIMs, by reprecipitation from a good solvent into a nonsolvent, showed similar microporosity, via gas adsorption, to the desired PIM product, despite their relatively low molecular mass. This observation suggested the development of the related concept of organic molecules of intrinsic microporosity (OMIMs). 
Biographical Sketch

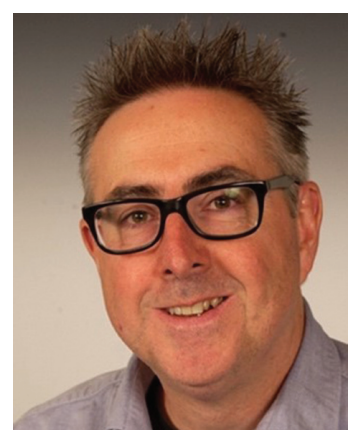

Neil B. McKeown, FRSC, FRSE, has occupied the Crawford Tercentenary Chair of Chemistry at The University of Edinburgh since 2014. He received his $\mathrm{PhD}$ in organic chemistry from the University of East Anglia in 1987. After postdoctoral research at York Univer- sity (Canada) and the University of Toronto, he obtained his first independentacademic post at the University of Manchester in 1991, then he moved to Cardiff University as a professor (2004-2014). His interests span many aspects of organic materials chemistry with particular emphasis on the synthesis of nanoporous molecular crystals and polymers of intrinsic microporosity (PIMs). For the latter, he was awarded the Beilby Medal (2008) and the Tilden Prize (2017) by the Royal Society of Chemistry.

\section{Theoretical Considerations Underpinning the OMIM Concept}

Organic molecules, on cooling from their melt or a saturated solution, tend to form solids in which they pack space efficiently so as to minimize the amount of void space. Although it has long been stated that "nature abhors a vacuum" (horror vacui), the molecular imperative is to maximize attractive intermolecular interactions. For the great majority of small organic molecules, the optimum packing efficiency is provided by a crystal structure, which typically gives a packing density $(\Phi)$ in the range of $0.67-0.77$, a value close to 0.74 obtained for an ordered array of closepacked spheres. However, organic molecules that possess "awkward" shapes and larger molecules, including many polymers, often crystallize slowly so that a solid amorphous glass forms preferentially on cooling the melt.

Such molecular glasses are similar in structure to noncrystalline polymers below their glass transition temperature (e.g., atactic polystyrene or a PIM). Translational molecular movement is frozen within a glass and so the molecules are kinetically trapped and are unable to rearrange themselves into the more thermodynamically stable crystal. Typically, the space efficiency for the packing of an organic molecule in a glass is around 5-10\% less than that of a densely packed crystal but, in most cases, this does not generate sufficient free volume to be considered microporous. However, if a molecule is designed to have a shape that is awkward to pack space, when it self-associates to form an amorphous solid it may trap sufficient free volume so that it acts as a microporous material-i.e., it possesses interconnected pores of less than $2 \mathrm{~nm}$ in diameter.

The most efficient arrangement for packing solid geometric shapes into a defined space has fascinated and challenged mathematicians for centuries and in recent years space-inefficient packing has also been considered by theory. In recent years, Torquato and coworkers have linked the various mathematical "packing problems" with the behavior of real particles and molecules by developing the concept of "random jamming," at which point the contact between the geometric shapes restricts their motion. ${ }^{15}$ Importantly, jamming can be correlated directly with the glass transition temperature $\left(T_{\mathrm{g}}\right)$ of a molecular material, at which point concerted molecular motions cease. Using a random jamming modeling technique, it was found that the maximum packing density of concave two-dimensional (2D) superdisks $^{16}$ and $3 \mathrm{D}$ superballs ${ }^{17}$ decreases with increasing concave faces, as space filling by mutual interpenetration (or interdigitation) becomes more difficult. It follows that molecules with large concavities will pack highly inefficiently leading to microporosity, which is the conceptual basis for the OMIMs. Cages and macrocycles represent an extreme example of a concavity whereby the internal space defined by the cage or ring is protected from the interpenetration of other molecules. ${ }^{18}$ Most cage- and macrocycle-based porous materials are crystalline in structure $^{7}$; however, Cooper et al. showed that suitably designed cages, provided by scrambled peripheral substituents, produce amorphous materials with significant porosity as determined by gas adsorption. ${ }^{19}$ The porosity of cages as amorphous solids has also been investigated by packing simulations. ${ }^{20}$

\section{Molecules with Concavities}

The archetypal molecule with obvious concavities is triptycene, for which Swager et al. introduced the concept of internal free volume (IFV; Figure 1). ${ }^{21}$ This concept was exploited for the design of triptycene-based dyes that orientate in liquid crystals, due to the rod-like molecules filling the triptycene concavities, or for generating highperformance dielectric materials from enhancing free volume in various classes of polymers such as polyimides. ${ }^{22}$ MacLachlan et al. also cited the concept of IFV in the design of rigid oligomeric triptycenes linked via metal-containing salphens $^{23}$ and shape-persistent triptycene-based oligomers. ${ }^{24}$ This concept of creating extended molecular structures using rigid metal-containing salphens was subsequently developed further by Mastalerz et al. using triptycene and tetrahedral 

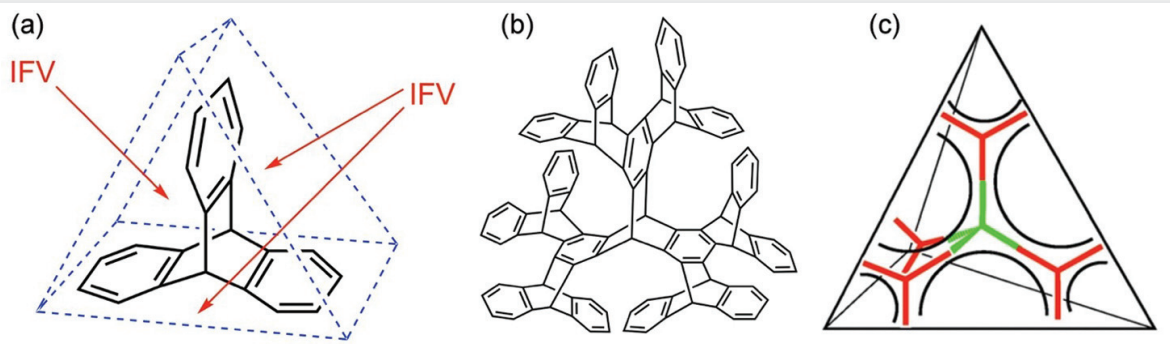

Figure 1 (a) The concept of internal free volume (IFV) demonstrated for the concavities of triptycene. (b) Hart's "supertriptycene" with pronounced concavities. (c) A cartoon representation of an OMIM composed of a tetrahedral core (e.g. spirobifluorine) and trigonal terminal groups (e.g., triptycene) for which the many concavities are shown.

tetraphenylmethane-building units. ${ }^{25}$ Some of these discrete molecules demonstrated porosity as amorphous powders via gas uptake with apparent BET (Brunauer-Emmett-Teller) surface areas $\left(\mathrm{SA}_{\mathrm{BET}}\right.$ ) of up to $600 \mathrm{~m}^{2} \mathrm{~g}^{-1}$. It should be noted that similar but purely organic oligo-triptycenes, termed iptycenes by Hart et al., ${ }^{26}$ were introduced in the 1980s and their potential for porosity based on the cavities generated by their molecular structures was recognized. In particular, Hart's beautifully symmetric "supertriptycene," perhaps the ultimate discrete iptycene, possesses many well-defined cavities and was reported to crystallize with a large amount of included solvent. ${ }^{27}$ It is likely that, if probed by gas adsorption, this organic molecule would produce a porous glassy material similar to those of the salphen-based triptycene oligomers ${ }^{23 \mathrm{~b}}$ and the OMIMs described below.

\section{The Synthesis and Properties of OMIMs}

It follows from the above discussion that the OMIM concept involves rigid discrete molecules, made by combining structural components with well-defined concavities, so that they pack space inefficiently, therefore, providing sufficient free volume for microporosity, as demonstrated by gas adsorption. The initial objective was to design OMIMs that could be prepared readily using dibenzodioxin formation via nucleophilic substitution, as utilized for PIM synthesis, and compare the experimental results obtained from gas adsorption with those from packing simulations (to be performed in collaboration with the group of Coray Colina). The first product to show this behavior (OMIM-1) was prepared via the dibenzodioxin-forming reaction between the easily prepared monomer 4,4'-dicyano$2,2^{\prime}, 3,3^{\prime} 5,5^{\prime}, 6,6^{\prime}$-octafluorobiphenyl, which acts as a tetrafunctional core, with 2,3-dihydroxytriptycene. OMIM-1 was introduced briefly in a 2010 review on PIMs to illustrate that intrinsic microporosity may be achieved by molecular components of modest size. ${ }^{13 c}$ It was proposed that dibenzodioxin formation could provide the basis of a modular approach to make OMIMs using a wide range of rigid monomeric components based on biphenyl (displaced cruciform), triptycene (trigonal), spirobifluorene (tetrahedral), and hexabenzopropellane (octahedral). Combinations of these differently shaped structural components, all with distinct concavities, could either be the core or the terminal groups of the OMIM (or both). An initial study, involving the simulated packing of OMIMs 1-3, each possessing a biphenyl core and possessing four triptycene, spirobifluorene, or hexabenzopropellane terminal groups, respectively, suggested that microporosity increases in the order of OMIM-2 < OMIM-1 < OMIM-3 (Figure 2). ${ }^{28}$ In addition, packing simulations suggested that the introduction of a $t$ butyl group onto the terminal triptycene, to give OMIM-4, enhanced microporosity further. Experimental analysis of OMIMs 1-4, using gas adsorption, confirmed the trend predicted by simulation (Figure $2 \mathrm{~b}$ ). ${ }^{29}$ However, attempts to publish this work as a collaboration between synthesis and simulation was frustrated by reviewers objecting to the differences in absolute values between apparent BET surface areas and micropore volumes obtained from packing simulations and those derived experimentally from gas adsorptions. These differences arose from swelling of the materials during gas adsorption analysis, which is difficult to model, although this has now been achieved by the Colina group for PIM-1 and other microporous materials using chain-packing simulations. ${ }^{30}$ Therefore, these interrelated studies were published separately, which diminished the unique aspect of this collaborative research program. ${ }^{29}$

The Colina group went on to predict intrinsic microporosity for a diverse range of OMIMs including those based on octahydroxy-spirobifluorene and dodecahydroxy-hexabenzopropellane cores, both of which proved difficult to use in a practical synthesis due to their oxidative instability. ${ }^{31}$ Conclusions from this packing simulation study were that the three structural design aspects for increasing porosity in OMIMs are (i) rigidity, (ii) bulky terminal groups such as t-butyl, and (iii) three-dimensionality of the core structure (i.e., 2D-triptycene-based cores allowed for more space efficient packing than 3D-spirobifluorene-based cores). In particular, the bulky terminal 

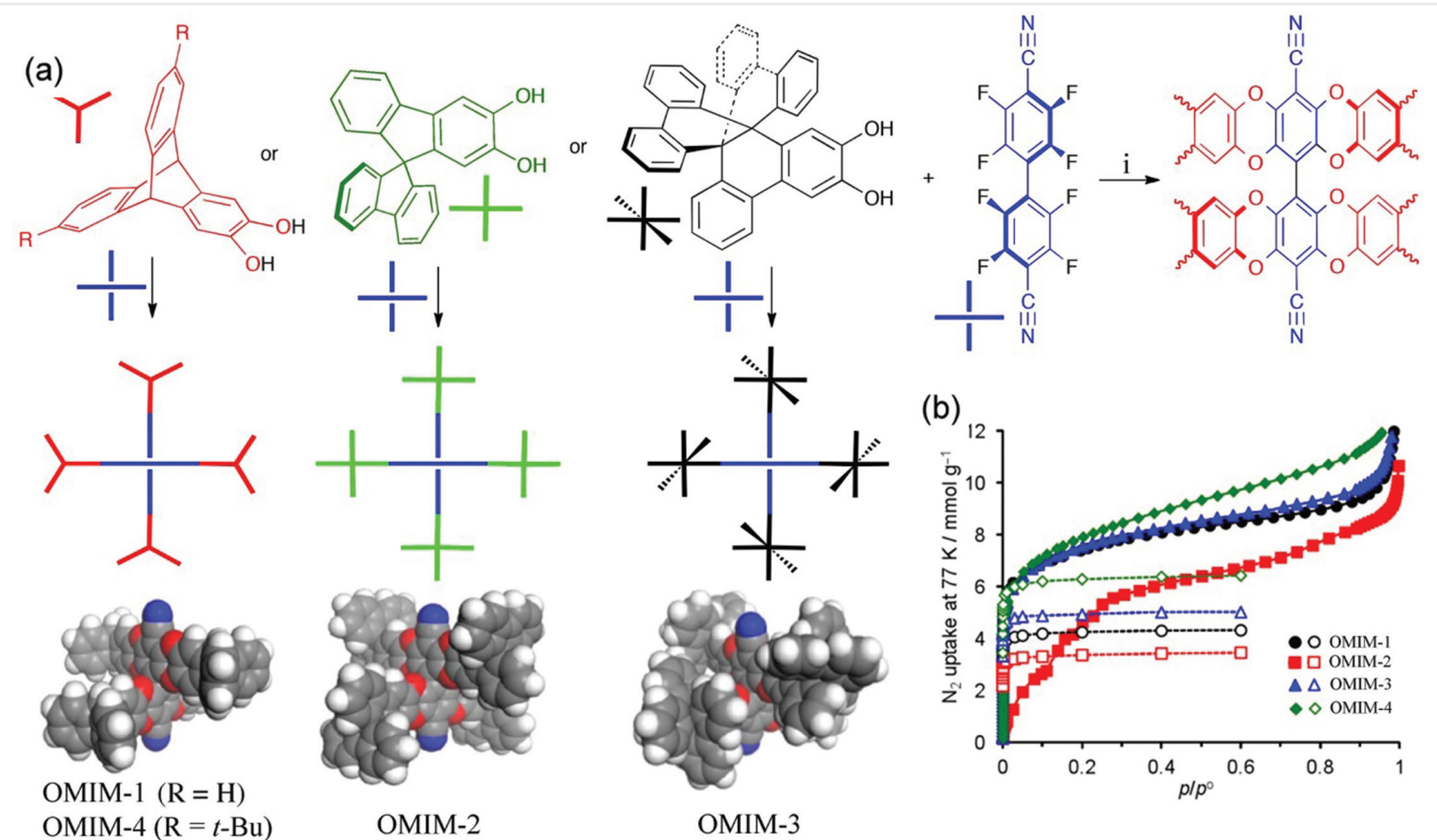

OMIM-1 $(\mathrm{R}=\mathrm{H})$

OMIM-4 $(\mathrm{R}=t$-Bu $)$

OMIM-8 $\left(\mathrm{R}=\mathrm{X}_{X}\right)$

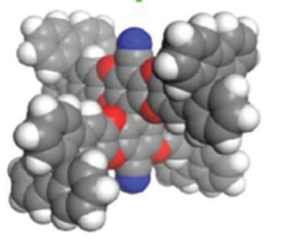

OMIM-2

OMIM-3

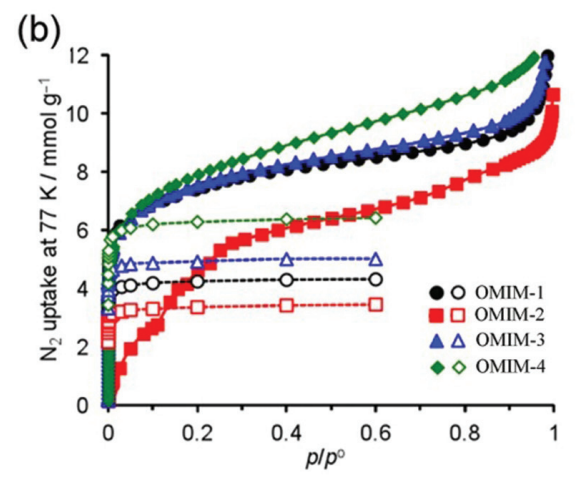

(b)

Figure 2 (a) The synthesis, cartoon representations, and molecular models of OMIMs 1-4. Reaction conditions: (i) $\mathrm{K}_{2} \mathrm{CO}_{3}, \mathrm{DMF}^{\circ} 60{ }^{\circ} \mathrm{C}$. (b) Nitrogen adsorption isotherms of OMIMs 1-4 collected at $77 \mathrm{~K}$ (filled symbols) and isotherms predicted from static packing models (empty symbols).

alkyl groups had the beneficial properties of increasing the dihedral angle between the phenyl rings of the biphenyl cores creating a more open structure. Subsequently, the results of a sustained program of synthesis showed that OMIMs could be produced with $\mathrm{SA}_{\mathrm{BET}}$ in the range of 300-700 $\mathrm{m}^{2} \mathrm{~g}^{-1}$, with the greatest microporosity demonstrated by OMIM-8, which possesses a biphenyl core with four triptycene arms terminated by a bulky cyclic substituent. ${ }^{32}$ The microporosity of OMIM-8 is comparable with that of PIM-1 (750-800 $\left.\mathrm{m}^{2} \mathrm{~g}^{-1}\right)$ and only a little less than the best-performing amorphous cages (up to $1,000 \mathrm{~m}^{2} \mathrm{~g}^{-1}$ ). Subsequent studies on the synthesis and characterization of OMIMs by Mastalerz et al. have involved the use of triptycene as the predominant building unit. These studies have used an interesting hexa-aminotriptycene starting material extended by the efficient reaction with o-quinone precursors. ${ }^{33}$ A similar strategy was used by Waldvogel et al. but instead employing an octa-aminospirobifluorene as the core unit. Several other OMIM-like molecules have been prepared but have not been investigated for potential intrinsic microporosity. ${ }^{34}$ The resulting triptycene- and spirobifluorene-centered molecules are closely related to those investigated by packing simulations. ${ }^{31}$

\section{Conclusions and Outlook}

It is important to consider why OMIMs are different from other microporous materials and why these differences might result in applications. As amorphous, solutionprocessable, organic materials, OMIMs share many of the same structural characteristics as those formed using PIMs. However, as PIMs are prepared via step-growth polymerization, they possess very large polydispersities-i.e., they are composed of a mixture of molecules with highly diverse molecular masses. Thus, a key difference, and potential advantage, is that OMIMs are discrete molecules, which, if prepared correctly, possess a single molecular mass. This property is best demonstrated by mass spectroscopic analysis, using an appropriate technique such as matrixassisted laser desorption/ionization mass spectrometry (MALDI-MS) to show a single parent ion (Figure 3c). Careful crystallization and analysis using single-crystal X-ray diffraction can even reveal the well-defined molecular structures of some OMIMs, despite their amorphous nature when rapidly precipitated from solution or cast as a thin film from solution (Figure 3a). ${ }^{32,33 b}$ Successful single crystal formation relies on the OMIM being composed of a single regioisomer (e.g., OMIM-1 and OMIM-8) and ensuring slow 

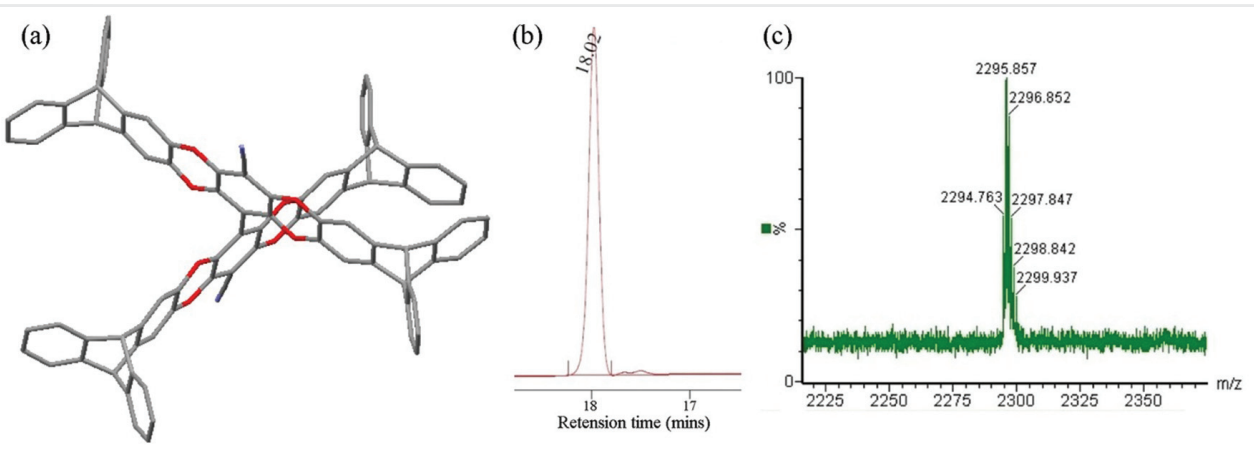

Figure 3 Characterization of OMIM-1 using (a) single-crystal X-ray diffraction; (b) gel permeation chromatography; and (c) MALDI-mass spectroscopy.

crystal growth from solution. ${ }^{32,33 b}$ For analysis using gel permeation chromatography (GPC), OMIMs display a polydispersity value (i.e., weight average molecular mass $M_{\mathrm{w}}$ /number average molecular mass $M_{\mathrm{n}}$ ), which is very close to unity, in clear contrast to the highly polydisperse PIMs $\left(M_{\mathrm{w}} / M_{\mathrm{n}}>2\right)$ (Figure 3b). Indeed, correctly prepared OMIMs may only deviate from an organic chemist's vision of perfection by possessing numerous regioisomers (and potentially stereoisomers) and these may account for the slight broadening of peaks in GPC that results in values for $M_{\mathrm{w}} / M_{\mathrm{n}}$ being slightly larger than unity due to small differences in hydrodynamic size between the regioisomers. It should also be noted that there may be significant deviation from the molecular mass of the OMIM calculated from GPC data due to the more compact hydrodynamic shape of the OMIMs relative to that of the polymer standards used to calibrate the GPC output (e.g., polystyrene). ${ }^{32}$ In addition, the large number of regioisomers possessed by some OMIMs may account for their extremely complex NMR spectra.

Despite the structural similarities of PIMs and OMIMs as amorphous organic solids, there is a clear difference in their film-forming properties. OMIMs tend to form brittle solids on solvent casting, which fracture into small fragments as the solvent evaporates, in contrast to the robust selfstanding films formed by PIMs. The mechanical robustness of PIM films is due to extensive chain entanglement, resulting from their high molecular mass, which is not possible for OMIMs. Therefore, OMIMs are best processed as thin supported films by using, for example, a spin-coating methodology. On the other hand, the viscosity of PIM solutions and their chain-extend size as macromolecules can be problematic for certain applications. For example, the infiltration of PIM solutions into macropores or mesopores is very challenging. Therefore, OMIMs may have applications in the preparation of composite materials with hierarchical porosity as their molecular diameters are generally only a few nanometers in diameter and they form nonviscous solutions suitable for infiltration into porous materials.

OMIMs were conceived as the focus of combined experimental and simulation studies to provide fundamental understanding on the solid-state packing of large rigid molecules containing concavities. However, their difference in properties from conventional porous materials does suggest potential applications. One possibility that has been investigated recently is their use as the stationary phase for gas chromatography for which their solution processability and thermal stability allow for facile coating and conditioning at moderately high temperatures ( 200 $\left.{ }^{\circ} \mathrm{C}\right)$. Very impressive separation performance was demonstrated for mixtures of isomers and for the separation of branched and nonbranched hydrocarbons. ${ }^{35}$ In a related application, OMIMs have also been used as in quartz microbalance sensors as affinity materials with some examples showing particular selectivity for precursors to illicit drugs. ${ }^{36}$ It is likely that further applications will be identified in the future based on the unique combination of properties offered by the OMIMs.

\section{Acknowledgments}

Many thanks are due to those who realized the concept of OMIMs using synthesis: Dr. Kadhum Msayib, Dr. C. Grazia Bezzu, Dr. Rupert Taylor, and Dr. Jonathan Walker, and by packing simulations: Prof. Coray Colina (University of Florida) and Dr. Lauren Abbott. I would also like to thank Prof. Peter Budd (University of Manchester) for valuable discussions.

\section{Funding Information}

The EPSRC, United Kingdom, is acknowledged for funding (EP/G065144 and EP/H024034). 


\section{References}

(1) Slater, A. G.; Cooper, A. I. Science 2015, 348, aaa8075.

(2) Kitagawa, S.; Kitaura, R.; Noro, S. Angew. Chem. Int. Ed. 2004, 43 , 2334.

(3) Furukawa, H.; Cordova, K. E.; O'Keeffe, M.; Yaghi, O. M. Science 2013, 341, 974.

(4) (a) Côté, A. P.; Benin, A. I.; Ockwig, N. W.; O'Keeffe, M.; Matzger, A. J.; Yaghi, O. M. Science 2005, 310, 1166. (b) Feng, X.; Ding, X.; Jiang, D. Chem. Soc. Rev. 2012, 41, 6010.

(5) Lin, R.-B.; He, Y.; Li, P.; Wang, H.; Zhou, W.; Chen, B. Chem. Soc. Rev. 2019, 48, 1362.

(6) (a) Evans, J. D.; Jelfs, K. E.; Day, G. M.; Doonan, C. J. Chem. Soc. Rev. 2017, 46, 3286. (b) Cooper, A. I. ACS Cent. Sci. 2017, 3, 544.

(7) (a) Tozawa, T.; Jones, J. T. A.; Swamy, S. I.; Jiang, S.; Adams, D. J.; Shakespeare, S.; Clowes, R.; Bradshaw, D.; Hasell, T.; Chong, S. Y.; Tang, C.; Thompson, S.; Parker, J.; Trewin, A.; Bacsa, J.; Slawin, A. MZ.; Steiner, A.; Cooper, A. I. Nat. Mater. 2009, 8, 973. (b) Mastalerz, M.; Schneider, M. W.; Oppel, I. M.; Presly, O. Angew. Chem. Int. Ed. 2011, 50, 1046. (c) Schneider, M. W.; Hauswald, H. J. S.; Stoll, R.; Mastalerz, M. Chem. Commun. 2012, 48, 9861. (d) Schneider, M. W.; Oppel, I. M.; Ott, H.; Lechner, L. G.; Hauswald, H. J. S.; Stoll, R.; Mastalerz, M. Chem. Eur. J. 2012, 18, 836. (e) Zhang, G.; Mastalerz, M. Chem. Soc. Rev. 2014, 43, 1934. (f) Zhang, G.; Presly, O.; White, F.; Oppel, I. M.; Mastalerz, M. Angew. Chem. Int. Ed. 2014, 53, 1516. (g) Hasell, T.; Cooper, A. I. Nat. Rev. Mater. 2016, 1, 16053. (h) Mastalerz, M. Acc. Chem. Res. 2018, 51, 2411.

(8) (a) Holst, J. R.; Trewin, A.; Cooper, A. I. Nat. Chem. 2010, 2, 915. (b) McKeown, N. B. Nat. Mater. 2011, 10, 563.

(9) (a) Sozzani, P.; Bracco, S.; Comotti, A.; Ferretti, L.; Simonutti, R. Angew. Chem. Int. Ed. 2005, 44, 1816. (b) Msayib, K. J.; Book, D.; Budd, P. M.; Chaukura, N.; Harris, K. D. M.; Helliwell, M.; Tedds, S.; Walton, A.; Warren, J. E.; Xu, M. C.; McKeown, N. B. Angew. Chem. Int. Ed. 2009, 48, 3273. (c) Bezzu, C. G.; Helliwell, M.; Warren, J. E.; Allan, D. R.; McKeown, N. B. Science 2010, 327, 1627. (d) Tian, J.; Thallapally, P. K.; McGrail, B. P. CrystEngComm 2012, 14, 1909.

(10) Tsyurupa, M. P.; Davankov, V. A. React. Funct. Polym. 2006, 66, 768.

(11) (a) Ghanem, B. S.; Hashem, M.; Harris, K. D. M.; Msayib, K. J.; Xu, M. C.; Budd, P. M.; Chaukura, N.; Book, D.; Tedds, S.; Walton, A.; McKeown, N. B. Macromolecules 2010, 43, 5287. (b) McKeown, N. B.; Hanif, S.; Msayib, K.; Tattershall, C. E.; Budd, P. M. Chem. Commun. 2002, 2782. (c) McKeown, N. B.; Makhseed, S.; Budd, P. M. Chem. Commun. 2002, 2780.

(12) Ben, T.; Ren, H.; Ma, S. Q.; Cao, D. P.; Lan, J. H.; Jing, X. F.; Wang, W. C.; Xu, J.; Deng, F.; Simmons, J. M.; Qiu, S. L.; Zhu, G. S. Angew. Chem. Int. Ed. 2009, 48, 9457.

(13) (a) Budd, P. M.; Ghanem, B. S.; Makhseed, S.; McKeown, N. B.; Msayib, K. J.; Tattershall, C. E. Chem. Commun. 2004, 230. (b) Budd, P. M.; McKeown, N. B.; Fritsch, D. Macromol. Symp. 2006 245, 403. (c) McKeown, N. B.; Budd, P. M. Macromolecules 2010, 43, 5163.

(14) Carta, M.; Malpass-Evans, R.; Croad, M.; Rogan, Y.; Jansen, J. C.; Bernardo, P.; Bazzarelli, F.; McKeown, N. B. Science 2013, 339, 303.

(15) Torquato, S.; Stillinger, F. H. Rev. Mod. Phys. 2010, 82, 2633.

(16) Jiao, Y.; Stillinger, F. H.; Torquato, S. Phys. Rev. Lett. 2008, 100, 245504.

(17) Jiao, Y.; Stillinger, F. H.; Torquato, S. Phys. Rev. E: Stat. Nonlinear Soft Matter Phys. 2009, 79, 041309.
(18) Jones, J. T. A.; Hasell, T.; Wu, X.; Bacsa, J.; Jelfs, K. E.; Schmidtmann, M.; Chong, S. Y.; Adams, D. J.; Trewin, A.; Schiffman, F.; Cora, F.; Slater, B.; Steiner, A.; Day, G. M.; Cooper, A. I. Nature 2011, 474, 367.

(19) (a) Bojdys, M. J.; Briggs, M. E.; Jones, J. T. A.; Adams, D. J.; Chong, S. Y.; Schmidtmann, M.; Cooper, A. I. J. Am. Chem. Soc. 2011, 133, 16566. (b) Jiang, S.; Jones, J. T. A.; Hasell, T.; Blythe, C. E.; Adams, D. J.; Trewin, A.; Cooper, A. I. Nat. Commun. 2011, 2, 207.

(20) (a) Jiang, S.; Jelfs, K. E.; Holden, D.; Hasell, T.; Chong, S. Y.; Haranczyk, M.; Trewin, A.; Cooper, A. I. J. Am. Chem. Soc. 2013 135, 17818. (b) Evans, J. D.; Huang, D. M.; Hill, M. R.; Sumby, C. J.; Sholl, D. S.; Thornton, A. W.; Doonan, C. J. J. Phys. Chem. C 2015, 119, 7746

(21) (a) Long, T. M.; Swager, T. M. Adv. Mater. 2001, 13, 601. (b) Swager, T. M. Acc. Chem. Res. 2008, 41, 1181. (c) Chong, J. H.; MacLachlan, M. J. Chem. Soc. Rev. 2009, 38, 3301.

(22) (a) Long, T. M.; Swager, T. M. J. Am. Chem. Soc. 2003, 125, 14113. (b) Amara, J. P.; Swager, T. M. Macromolecules 2004, 37, 3068.

(23) (a) Chong, J. H.; Ardakani, S. J.; Smith, K. J.; MacLachlan, M. J. Chem. Eur. J. 2009, 15, 11824. (b) Crane, A. K.; MacLachlan, M. J. Eur. J. Inorg. Chem. 2012, 17.

(24) Chong, J. H.; MacLachlan, M. J. J. Org. Chem. 2007, 72, 8683.

(25) (a) Mastalerz, M.; Oppel, I. M. Eur. J. Org. Chem. 2011, 5971. (b) Reinhard, D.; Zhang, W. S.; Rominger, F.; Curticean, R.; Wacker, I.; Schroder, R. R.; Mastalerz, M. Chem. Eur. J. 2018, 24, 11433.

(26) (a) Ma, Y. X.; Meng, Z.; Chen, C. F. Synlett 2015, 26, 6. (b) Hart, H.; Bashirhashemi, A.; Luo, J.; Meador, M. A. Tetrahedron 1986, 42, 1641.

(27) (a) Shahlai, K.; Hart, H. J. Am. Chem. Soc. 1990, 112, 3687. (b) Shahlai, K.; Hart, H. J. Org. Chem. 1991, 56, 6905.

(28) Abbott, L. J.; McDermott, A. G.; Del Regno, A.; Taylor, R. G. D.; Bezzu, C. G.; Msayib, K. J.; McKeown, N. B.; Siperstein, F. R.; Runt, J.; Colina, C. M. J. Phys. Chem. B 2013, 117, 355.

(29) Taylor, R. G. D.; Carta, M.; Bezzu, C. G.; Walker, J.; Msayib, K. J.; Kariuki, B. M.; McKeown, N. B. Org. Lett. 2014, 16, 1848.

(30) (a) Kupgan, G.; Abbott, L. J.; Hart, K. E.; Colina, C. M. Chem. Rev. 2018, 118, 5488. (b) Hart, K. E.; Springmeier, J. M.; McKeown, N. B.; Colina, C. M. Phys. Chem. Chem. Phys. 2013, 15, 20161.

(31) Abbott, L. J.; McKeown, N. B.; Colina, C. M. J. Mater. Chem. A 2013, $1,11950$.

(32) Taylor, R. G. D.; Bezzu, C. G.; Carta, M.; Msayib, K. J.; Walker, J.; Short, R.; Kariuki, B. M.; McKeown, N. B. Chem. Eur. J. 2016, 22, 2466.

(33) (a) Kohl, B.; Rominger, F.; Mastalerz, M. Org. Lett. 2014, 16, 704 (b) Kohl, B.; Rominger, F.; Mastalerz, M. Chem. Eur. J. 2015, 21, 17308.

(34) (a) Mughal, E. U.; Eberhard, J.; Kuck, D. Chem. Eur. J. 2013, 19, 16029. (b) Zhu, P. C.; Liu, Y.; Peng, L. H.; Zhang, C. Tetrahedron Lett. 2014, 55, 521. (c) Reinhard, D.; Rominger, F.; Mastalerz, M. J. Org. Chem. 2015, 80, 9342. (d) Lucchesini, F.; Grasse, M.; Neumann, B.; Stammler, H. G.; Tellenbroker, J.; Kuck, D. Eur. J. Org. Chem. 2016, 2828. (e) Hu, Y.; Wang, D.; Baumgarten, M.; Schollmeyer, D.; Müllen, K.; Narita, A. Chem. Commun. 2018, 54, 13575.

(35) Weidman, J. R.; Guo, R. L. Ind. Eng. Chem. Res. 2017, 56, 4220.

(36) (a) Pyka, I.; Lubczyk, D.; Saiju, M. D. S.; Salbeck, J.; Waldvogel, S. R. ChemPlusChem 2017, 82, 1116. (b) Pyka, I.; Nikl, J.; Schollmeyer, D.; Waldvogel, S. R. Eur. J. Org. Chem. 2017, 3501. (c) Prantl, E.; Kohl, B.; Ryvlin, D.; Biegger, P.; Wadepohl, H.; Rominger, F.; Bunz, U. H. F.; Mastalerz, M.; Waldvogel, S. R. ChemPlusChem 2019, 84, 1239. 